\title{
Tecnologia educacional como estratégia de empoderamento de pessoas com enfermidades crônicas
}

\section{Educational technology as a strategy for the empowerment of people with chronic illnesses \\ Tecnología educacional como estrategia de empoderamiento de personas con enfermedades crónicas}

\author{
Lina Márcia Miguéis Berardinelli'; Nathália Aparecida Costa Guedes ${ }^{I I}$; \\ Juliana Pereira Ramos ${ }^{\text {III }}$; Michelle Garcia Nascimento e Silva ${ }^{I V}$
}

\begin{abstract}
RESUMO: Os objetivos deste estudo foram: desenvolver o trabalho em grupo a fim de conhecer o cotidiano e o processo saúde/adoecimento/cuidado das pessoas com enfermidades crônicas; e analisar se o trabalho de grupo potencializou o empoderamento e que tecnologia educacional é recomendada nas práticas educativas para essas pessoas. Estudo descritivo, desenvolvido com 16 pessoas de uma instituição universitária, situada no município do Rio de Janeiro. Os dados foram coletados em 2014, por meio de entrevista semiestruturada, e submetidos às análises estatística e de conteúdo. Emergiram três categorias: A vida como ela é; Potencialidades para o empoderamento; e Tecnologias - o que eu prefiro. O cotidiano foi revelado por dor física, choro, estresse, alteração do humor. Conclui-se que a tecnologia educacional pode ser usada como estratégia de empoderamento de pessoas, considerando o envolvimento delas no grupo e o estímulo à reflexão, ao raciocínio, à troca de ideias e ao respeito mútuo.
\end{abstract}

Palavras-Chave: Empoderamento; tecnologia educacional; enfermagem; doença crônica.

ABSTRACT: This study aimed at [1] developing team work in order to learn about routine and health/illness/care process of persons with chronic diseases; and at [2] analyzing whether team work has leveraged empowerment and what educational technology should be used in the educational practices by persons with chronic health conditions. A descriptive and exploratory study, developed with 16 people of an academic institution located in the municipality of Rio de Janeiro, RJ, Brazil. Data were collected in 2014 by means of semi-structured interview and treated with statistic and content analysis. Three categories stood out: Life as it is; Potential for empowerment and Technologies; which one I prefer. Routine was unveiled by physical pain, tears, stress, and change in mood. Conclusions show that educational technology may be used as an empowering strategy, considering people's involvement in the group and their stimulation to reflection, exchange of ideas, and mutual respect. Keywords: Empowerment; educational technology; nursing; chronic disease.

RESUMEN: Los objetivos de este estudio fueron: desarrollar el trabajo en grupo con el fin de conocer el cotidiano y el proceso salud/enfermedad/atención de personas con enfermedades crónicas; y analizar si el trabajo en grupo ha mejorado la capacitación y cual tecnología educacional es recomendada en las prácticas educativas para esas personas. Estudio descriptivo, realizado con 16 clientes en una institución de educación superior, ubicada en el municipio de Río de Janeiro, Brasil. Los datos fueron recolectados en 2014, a través de entrevista semestructurada y fueron sometidos a los análises estadístico y de contenido. Emergieron tres categorías: La vida tal como es; Potencialidades para el empoderamiento; y Tecnologías - lo que yo prefiero. El cotidiano fue revelado por el dolor físico, el llanto, el estrés, los cambios de humor. En conclusión, la tecnología educacional se puede utilizar como estrategia de empoderamiento de personas, teniendo en cuenta su participación en el grupo y el estímulo a la reflexión, al razonamiento, al intercambio de ideas y al respeto mutuo.

Palabras Clave: Empoderamiento; tecnología educacional; enfermería; enfermedad crónica.

\section{INTRODUÇÃO}

As situações crônicas de saúde exigem dos indivíduos acompanhamento regular, parceria, desenvolvimento de vínculo, envolvimento, motivação e conhecimento sobre o autocuidado. Considera-se este fato, devido às evidências relatadas das dificuldades em superar a fragmentação das ações e serviços de saúde e qualificar o cuidado em saúde no contexto atual.

Por outro lado, o surgimento das doenças crônicas não transmissíveis (DCNT) relaciona-se às múltiplas causas, início gradual, prognóstico incerto

\footnotetext{
IEnfermeira. Professora Adjunta do Departamento de Enfermagem Médico-Cirúrgica e do Programa de Pós-Graduação da Faculdade de Enfermagem da Universidade do Estado do Rio de Janeiro. Bolsista do Programa de Incentivo à Produção, Técnica e Artística (Prociência), da Universidade do Estado do Rio de Janeiro. Brasil. E-mail: 1.m.b@uol.com.br

IIEnfermeira. Mestranda do Programa de Pós-Graduação da Faculdade de Enfermagem da Universidade do Estado do Rio de Janeiro. Brasil. E-mail: nathyyguedes@gmail.com

III Aluna do 7º Período do Curso de Graduação da Faculdade de Enfermagem da Universidade do Estado do Rio de Janeiro. Bolsista de Iniciação Científica, Conselho Nacional de Desenvolvimento Científico e Tecnológico. Rio de Janeiro, Brasil. E-mail: julianapereiraramos@gamil.com

IVEnfermeira. Mestranda do Programa de Pós-Graduação da Faculdade de Enfermagem da Universidade do Estado do Rio de Janeiro. Brasil. E-mail: ltmichelita@gmail.com
} 
e com longa e indefinida duração. Para tanto, as recomendações de cuidado requerem usualmente intervenções de tecnologia leves, leve-duras e duras, associadas à mudança de estilo de vida, em um processo de cuidado contínuo que não leva a cura ${ }^{1}$.

As tecnologias são processos concretizados a partir da experiência cotidiana do cuidar em saúde e algumas, derivadas de pesquisa para o desenvolvimento de um conjunto de atividades produzidas e controladas pelos seres humanos. Serve para gerar e aplicar conhecimentos, dominar processos e produtos e transformar a utilização empírica, de modo a torná-la uma abordagem cientifica ${ }^{2}$.

A função da tecnologia é potencializar as habilidades do próprio indivíduo, e/ou auxiliar na aquisição de novas atitudes buscando uma transformação de si mesmo. As tecnologias são categorizadas na área da saúde da seguinte maneira: tecnologia dura representada pelo material, equipamento, instalação física, ferramentas; tecnologia leve-dura que inclui os saberes estruturados no campo da saúde; tecnologia leve onde insere o processo de produção da comunicação e as relações ${ }^{3}$.

De igual maneira, a classificação da tecnologia proposta por enfermeiros baseia-se em: tecnologia educacional representada pelo conjunto de conhecimentos científicos que envolve o processo educacional; tecnologia assistencial, incluindo as ações sistematizadas para uma assistência qualificada; tecnologia gerencial como processo sistematizado composto por ações teórico-práticas utilizadas no gerenciamento da assistência ${ }^{4}$.

O enfermeiro no seu cotidiano vivencia situações nas quais a ação de enfermagem é direcionada para a educação no âmbito da saúde e dada à natureza da sua função, como profissional agenciador de conhecimentos, pode buscar opções que lhe ofereçam suporte para intervir junto às pessoas, grupos e comunidades, com vistas a favorecer o bem-estar, inclusão social e cidadania.

Complementando a ideia anterior e considerando a complexidade das situações que envolvem o processo saúde-doença, como os fatores biológicos, econômicos, sociais e culturais, bem como suas interligações e consequências, há necessidade de se investir em promoção da saúde. É, nesse contexto, que se coloca a discussão sobre o empoderamento, enfocando-se a atenção para intervenções que extrapolam o criticado modelo biomédico.

Assim, diante do exposto, destaca-se a seguinte questão: a tecnologia educacional pode ser usada como estratégia de empoderamento de pessoas em situação crônica de saúde? Portanto, os objetivos foram: desenvolver o trabalho em grupo a fim de conhecer o cotidiano e o processo saúde/adoecimento/cuidado das pessoas com enfermidades crônicas; analisar se o trabalho de grupo potencializou o empoderamento e que tecnologia educacional é recomendada nas práticas educativas para essas pessoas.

\section{REVISÃo DE Literatura}

Os enfermeiros podem colaborar na promoção da saúde, sendo necessária mudança no relacionamento entre profissionais e comunidade, no qual as parcerias devem ser mais valorizadas que as abordagens individuais e paternalistas. Pois, acredita-se que parceiros sejam indivíduos capazes que se tornam ainda mais habilitados quando compartilham conhecimento, habilidades e recursos ${ }^{5}$. Principalmente, quando os encontros em grupos se tornam espaço de acolhimento, de partilha de experiências de vida, de sentimentos e vivências das situações da vida, conforme estudos comprovados ${ }^{6}$. Nesses casos, atesta-se a mobilização de recursos e competências das pessoas por meio da ação motivadora do próprio grupo, favorecendo a formação de uma rede social solidária para enfrentar os problemas do cotidiano.

Assim, a tecnologia educacional no cuidado de enfermagem, pode ser uma importante ferramenta que auxilie no cuidado às pessoas, possibilitando ainda desenvolver novas formas de cuidado que auxilie os profissionais para o ensino do autocuidado e no desenvolvimento de competências?

Estudiosos da área argumentam que as tecnologias educacionais podem ser entendidas como ferramentas utilizadas para ampliar e potencializar o empoderamento das pessoas ${ }^{2,7,8}$. $\mathrm{O}$ empoderamento é um conceito polissêmico que tem tido visibilidade crescente, principalmente a partir dos anos 1990, tendo sua origem na língua inglesa, empowerment? No entanto, este foi modificado e reinterpretado por diversos autores ${ }^{9}$.

Dessa maneira, é compreendido como o $\mathrm{au} \neg$ mento do poder e autonomia pessoal e coletiva de indiví-duos e grupos sociais nas relações interpessoais e institu $\neg$ cionais $^{10}$. Da mesma forma, este conceito tem assumido significações que se referem ao desenvolvimento de potencialidades, aumento de informação e percepção, com o objetivo de que exista uma participação real e simbólica que possibilite a democracia ${ }^{11}$.

Por outro lado, o empoderamento é um processo educativo proposto a ajudar as pessoas a ampliar conhecimentos, habilidades, atitudes e autoconhecimento necessários para assumir com sucesso a responsabilidade com as decisões acerca de sua saúde ${ }^{12}$. Além disso, capacita o indivíduo a resolver os seus próprios problemas e necessidades, a compreender como pode solucionar esses problemas com os seus próprios recursos ou com apoios externos e a promover ações mais apropriadas para fomentar uma vida saudável ${ }^{7}$. 
O escopo teórico remete à aprendizagem dialógica, desenvolvimento de posicionamento crítico no qual o indivíduo ressignifica o seu modo de viver saudável próprio/autônomo/personalizado. Ressaltando que somente a informação, compartilhada nos processos educativos, por si só não modificará os comportamentos em relação à situação problema. Embora o conhecimento seja uma condição necessária para que ocorra o processo de mudança de certa prática ou comportamento, outras variáveis como a atitude terão de ser mudadas para que determinado comportamento prejudicial seja modificado ${ }^{13}$.

Pode-se afirmar que pessoas mais informadas, envolvidas e responsabilizadas, ou seja, empoderadas interagem de forma mais eficaz com os profissionais de saúde tentando realizar ações que produzam resultados de saúde ${ }^{7}$. Nessa perspectiva é possível capacitar as pessoas para que elas aprendam, nas diversas fases do processo de viver, a enfrentar as possíveis enfermidades crônicas que afetam a saúde ${ }^{14}$.

Diante das circunstâncias mundiais, em que pese as discussões sobre as DCNT, estudiosos têm apontado que os maiores problemas são consequências das dificuldades de mudanças dos modelos de saúde e das práticas de cuidado, as quais precisam ser inovadas para qualificar o atendimento das necessidades e interesses da população ${ }^{15}$.

Nesse caso, se entendido o processo saúdeadoecimento-cuidado, os indivíduos passam a usufruir de maior autonomia e qualidade de vida. Resultados de estudo têm mostrado que no domínio de promoção à saúde, o tratamento tem que se estender para além dos limites da clínica e permear o ambiente doméstico. Os pacientes e os familiares necessitam de apoio e auxílio. $\mathrm{O}$ tratamento para as DCNT deve ser reorientado em torno do paciente e da família?.

\section{Metodologia}

Trata-se de um estudo descritivo, desenvolvido no Laboratório Saúde (LABSAÚDE) do Instituto de Educação Física e dos Desportos da Universidade do Estado do Rio de Janeiro (UERJ) em 2014. Os sujeitos foram 16 pacientes, cujos critérios de inclusão especificavam: diagnóstico e/ou histórico familiar de DCNT, faixa etária acima de 20 anos, participantes das atividades dos projetos do LABSAÚDE, sem distinção de raça, sexo, religião, interessados em participar de todas as etapas de desenvolvimento da pesquisa de forma voluntária.

O estudo foi aprovado pelo Comitê de Ética da UERJ, atendendo à Resolução no 466/2012 do Conselho Nacional de Saúde de pesquisas envolvendo seres humanos, sob o protocolo $\mathrm{n}^{\circ}$ 017.3.3012.

A participação dos sujeitos no estudo se condicionou à assinatura do Termo de Consentimento
Livre e Esclarecido, após a leitura e a compreensão dos procedimentos éticos sobre o anonimato, os objetivos, as vantagens e desvantagens quanto à implementação da pesquisa.

Os dados foram produzidos através de entrevista semiestruturada, individual, com questões específicas do estudo, gravadas em aparelho eletrônico MP3, apoiada por um roteiro previamente testado. Os sujeitos foram identificados como entrevistado 1 (E 1) e, assim sucessivamente.

Aplicou-se a técnica de saturação de dados para limitar o conjunto de clientes. A partir da $17^{\mathrm{a}}$ entrevista, as respostas começaram a se repetir, encerrandose a coleta de dados com 16 sujeitos.

$\mathrm{Na}$ abordagem quantitativa, as variáveis sociodemográficas e clínicas foram submetidas à análise estatística, com cálculos de frequências absolutas e percentuais.

De igual maneira, na abordagem qualitativa, os dados foram transcritos, organizados, distribuídos cronologicamente de acordo com as respostas, classificados e categorizados, segundo o método da análise de conteúdo ${ }^{16}$. Dos depoimentos emergirm três categorias denominadas: A vida como ela é; Potencialidades para o empoderamento; e Tecnologias - o que eu prefiro.

\section{Resultados e Discussão}

\section{Perfil dos participantes}

Inicia-se esta seção com a descrição dos dados sociodemográficos dos sujeitos da pesquisa. Dos 16 clientes, $2(12.5 \%)$ são do sexo masculino e $14(87.5 \%)$ do sexo feminino. Sendo que a idade varia de 44 a 83 anos, no entanto, a metade está acima de 71 anos.

Quanto à escolaridade, 7(43,75\%) possuem somente o Ensino Fundamental, 6 (37,5\%) cursaram o Ensino Médio e 3(18,75\%) com nível superior completo. Sobre a etnia, $6(37,5 \%)$ se autodeclararam negros, $6(37,5 \%)$ são brancos e $4(25 \%)$ pardos. Da crença religiosa, $10(62,5 \%)$ são católicos, $1(6,25 \%)$ é protestante, $1(6,25 \%)$, é messiânico, $2(12,5 \%)$ são espíritas e 2(12,5) são testemunhas de Jeová. Quanto à ocupação, $10(62,5 \%)$ são aposentados, $2(12,5 \%)$ são autônomos, $2(12,5 \%)$ são do lar e 2(12,5\%) são trabalhadores formais.

Em se tratando da renda, 5(31,25\%) recebem entre 1 a 2 salários mínimos, $7(43,75 \%)$ de 3 a 4 salários mínimos, 3(18,75\%) de 4 a 6 salários mínimos e 1(6,25\%) recebia acima de 10 salários mínimos. A maioria é residente nos bairros da Zona Norte do Rio de Janeiro.

Do ponto de vista clínico, 4(25\%) possuem fibromialgia, 1(6,25\%) lúpus, 6(37,5\%) hipertensão arterial sistêmica (HAS), 1(6,25\%) Parkinson, 2 $(12,5 \%)$ cardiopatia, $1(6,25 \%)$ fibromialgia associada 
à HAS e Diabetes, e 1(6,25\%) alegou que não possui nenhum tipo de patologia, mas tem história familiar de doença crônica e que frequenta as atividades do grupo, para se manter saudável.

Nesse grupo, pode-se avaliar que a maioria é constituída por mulher, aposentada, com baixa escolaridade, baixa condição socioeconômica, pertencente à religião católica, e do ponto de vista clínico possui uma ou mais enfermidades crônicas. Os resultados mostram que se encontram engajadas nas atividades do grupo, para o processo de conhecimento, autocuidado, qualidade de vida e autonomia.

A seguir são analisadas as categorias emergentes.

\section{A vida como ela é}

Esta categoria emergiu após uma dinâmica de grupo, evidenciando o cotidiano dos participantes no encontro tácito com os problemas crônicos, expressando a forma como cada um vivenciou o momento e suas repercussões, conforme mostram os seguintes relatos:

O meu dia a dia não tem sido bom depois que descobri a fribromialgia, uns 8 a 9 anos atrás, por acaso, [...] sentia muita dor, chorava [...] achavam que eu era muito estressada. O que mais me incomoda é a ignorância das pessoas, porque 4 anos atrás ninguém havia falado em fibromialgia. A ignorância é grande, começa na família. (E1)

Hoje meu dia a dia é quase normal [...] mas antes eu andava toda travada, hoje faço minhas atividades normais. Tenho lúpus também. Nunca tive uma crise séria, faço o tratamento. O que incomoda é o aborrecimento [...] onde a Lucia detona, trabalha bem isso no grupo. (E2)

Tentei melhorar o meu dia a dia, fui ao médico, fiz tratamentos, e quem descobriu a fibromialgia foi um dentista, porque eu estava quebrando todos os meus blocos [...] melhorei mesmo foi, aqui, no grupo da UERJ, porque aqui tem a psicoterapia em grupo. O que me incomoda muito é o barulho, não porque eu trabalho em escola, sons altos não me fazem bem. (E5)

[...] um dia feliz, outro triste, deprimi, chorei, me achei incapaz, porque tudo aquilo que eu fazia não conseguia fazer mais, não conseguia andar, eu me arrastava, praticamente inerte. [...] graças a Deus hoje eu ando. Sempre fui hipertensa, desde os 20 anos e agora diabética. Incomoda dor, glicose alta e dormência no braço (E15)

Após a dinâmica de grupo, os participantes apontam controvertidas sensações e sentimentos ocorridos na vida ao se deparar com a realidade e relatados por quem de fato vivenciou a experiência. $O$ cotidiano foi revelado por dor física, choro, estresse, por não conseguir realizar as atividades, pela imobilidade, cansaço físico, dormência, depressão, alteração do humor. Acrescenta-se a isso, os desconfortos causados pela ignorância, aborrecimentos, frustrações, desânimo, limitações e desprezo.
As estratégias tecnológicas modificaram a forma de viver de grande parte da humanidade. No entanto, o trabalho realizado com a dinâmica de grupo é um grande desafio para todos enfermeiros e profissionais de saúde quando se almeja criar o exercício de compartilhamento, vivências e práticas de saúde na forma de construção coletiva.

Vale reforçar que o trabalho em grupo é a mola propulsora para revelações que muito poderão contribuir no processo ensino-aprendizagem de pessoas que vivenciam situações crônicas de saúde, na tentativa de se repensar novas tecnologias como estratégia de educação para o empoderamento, além de novos caminhos para o cuidado ${ }^{17}$.

Educação empoderada ou educação de empoderamento (empowerment education) é uma efetiva educação saudável e um modelo preventivo que se focaliza na ação grupal e no diálogo direto dos alvos comunitários, almejando aumentar a credibilidade das pessoas em sua capacidade em mudar suas próprias vidas ${ }^{18}$.

Nos depoimentos, a seguir, os participantes se expressam sobre a sua situação de saúde:

[...] ficamos sabendo de algumas coisas, os gatilhos, é uma doença dificil de controlar, extremamente dolorosa. Não tem tratamento e o fim é muito triste. Muitos não aceitam, porque acham que é problema da cabeça. Quanto mais saber sobre ela, melhor. (E2)

[...] sei que ela causa dores nas costas e ombros e articulações que incham e incomodam, tem dia que ela não me deixa trabalhar direito. Com o grupo pretendo saber mais. (E3)

[...] aprendi que é uma doença autoimune que não tem cura, que a gente pode controlar e viver bem, de acordo com a gente tem e procurar o que está nos fazendo mal, o que aciona o gatilho [...] exemplo, dou aula no município de Nova Friburgo e, lá, é muito frio. Semana passada fez 2 graus, mesmo tomando medicação, tomando bando quente e com agasalho eu continuei sentindo dor. (E5)

Eu acho uma desgraça, de modo geral, lá em casa, minhas irmãs (seis mulheres) e um homem, então com 60 anos de idade, todas elas ficaram hipertensas, ai quando fiz 60 fiquei hipertensa também. Só pode ser familiar. (E6)

Pode ser hereditária. É preciso não abusar de sal, essas coisas, nunca deixar de fazer uma atividade, não ficar parada, é mais ou menos isto. E se tiver mais alguma coisa, quero que me diga para eu ficar sabendo. Quero saber mais e mais, cada dia mais. (E9)

Como pode ser constatado nesses últimos depoimentos, mesmo que as pessoas possuam limitado conhecimento sobre o processo saúde/adoecimento, todas sinalizam o interesse em adquirir conhecimentos. Isso é um indicativo de que estão abertas a novas aprendizagens. 
A estratégia da tecnologia educacional traz muitos benefícios às práticas educativas, no entanto, para muitos profissionais de saúde, ainda é uma alternativa distante da realidade dos serviços de saúde. $\bigcirc$ trabalho em grupo envolve todos da equipe, tanto para organização de toda sequência como a tomada de decisões e favorece a vivência do sentimento de acolhimento, de pertencimento, os relatos e o compartilhamento de suas experiências cotidianas, ao lidar com as suas histórias de saúde.

Estudiosos referem que a relação entre empoderamento e educação para a saúde delineia um modelo de empoderamento como forma alternativa para os modelos mais tradicionais ${ }^{19}$. Ressaltam-se as três abordagens básicas empregadas para desenvolver as intervenções em educação em saúde: Modelo Preventivo, que focaliza o processo de decisão individual em adotar um comportamento saudável, para a prevenção de doenças; Modelo Político radical, onde o foco é a mudança social, ambiental e de estruturas políticas, para atacar a raiz dos problemas de saúde e doença; e finalmente, o Modelo de Empoderamento, cujo escopo é facilitar as escolhas individuais e comunitárias, para a aquisição de conhecimento com clarificação de valores e decisão, tornando prática as habilidades de organização comunitária, através de métodos de ensino não tradicional ${ }^{20}$.

\section{Potencialidades para o empoderamento}

Os participantes foram interrogados se receberam algum tipo de orientação de saúde e de que forma gostariam de ser orientados durante o acompanhamento, sendo constatado o seguinte:

Sim, no laboratório da educação física. No grupo que trata fibromialgia. Aqui, a gente aprendeu a [ter] nossa responsabilidade e a se conhecer. Você tem que ser muito forte, as pessoas dizem que você não tem nada. (E4)

Não recebi informação nenhuma. Tudo que sei foi da experiência com o grupo. Mas se pudesse escolher, gostaria de palestras, em grupo, é sempre bom saber sobre o que a gente tem. (E5)

Não, somente aqui no grupo da UERJ, com esse professor, ele foi me explicando... Estou tendo o maior aprendizado, eles estão falando a cada hora de um assunto. Quero aprender mais sim. É melhor conhecer para saber reagir. (E6)

Claro que sim, eu já sabia muita coisa. Aqui [no grupo] tudo é orientado, desde a turma iniciante, fazendo a ginástica de acordo com o que pode fazer, sem exagero. Depois de um tempo, fui melhorando. Quando comecei, tomava um diurético, dois remédios para a hipertensão, e sinvastatina para o colesterol. (E9)

A gente sabe que é uma doença crônica e que não há um tratamento especifico para ela. Eu acho que na realidade você tem que ter aceitação, mas lutar contra ela. Sobre o diabetes, já atingiu a função renal, sou hipertensa grave e severa. Recebi e ainda estou recebendo, muito apoio, graças a Deus, muita orientação. Aqui somos tratados como gente, nós conseguimos falar, a gente consegue colocar o que sente. (E13)

Após a dinâmica realizada em grupo, os sujeitos revelam em parte que conhecem os seus problemas de saúde, aqueles que conhecem pouco, e ainda estão no processo de aprendizagem, foram sinceros em dizer que aprenderam na ocasião, nas discussões em grupo, ou que pelos menos conseguiram falar o que estavam sentindo. E com isso se sentiram gente. Exercitaram a democracia e a cidadania.

Nesse sentido, as pessoas, ao se revelarem para o grupo, criam um movimento de intervenção e interação, todos acabam conhecendo o problema do outro e se ajudam com os relatos das experiências em determinadas situações. $\mathrm{O}$ acolhimento e o respeito ao outro são aspectos fundamentais. Nesse processo, todos são corresponsáveis na busca de soluções para sofrimentos e problemas cotidianos. Todos os comentários são relevantes e incluídos no grupo ${ }^{21}$. Portanto, construir esta realidade, que possibilite discutir a intenção educativa, representa a possibilidade de mudança no processo de ensino e aprendizagem e, paralelamente, a certeza de que estão sendo empoderados. Além disso, percebe-se que os coordenadores do grupo estão cumprindo sua real função.

\section{Tecnologias - o que eu prefiro}

Sobre o aspecto da tecnologia educacional como estratégia para o empoderamento de pessoas com problemas crônicos de saúde, os participantes declararam que:

Do jeito que está sendo feito hoje [em grupo], com palestras de vários profissionais. Aqui, você aprende que tem que cuidar de você primeiro. (E2)

[...] dinâmica em grupo é muito boa, é bom saber que tem outras pessoas com a mesma situação da gente e como elas se cuidam também. (E3)

[...] palestra, às vezes vem um especialista para falar no grupo. A Lucia, professora, está sempre comentando sobre outras doenças. Pode ser através dessas dinâmicas, palestras e internet, com tanto que eu receba as informações. (E5)

Assistindo, quem me orienta. Desenvolvendo meu raciocínio. Também gosto de ter algo escrito, porque você pode relembrar e se orientar em qualquer lugar. (E10)

Grupos de informações, panfletos informativos, reuniões, dinâmicas. Isso nos ajuda muito, nos dá força. (E15)

O posicionamento dos participantes foi unânime ao afirmar que gostariam de manter a estratégia das dinâmicas de grupo, palestras, levando-os a refletir, desenvolvendo o raciocínio e participando ativamente.

Assim, organizar o trabalho pedagógico, que reflita a intencionalidade da ação educativa, e formalizar esta intenção, num plano, pressupõem superar o caráter fragmentado das práticas educativas e atingir as metas da estratégia educacional. 
Dessa forma, definir, coletivamente, as condições necessárias para que se realize este processo, faz parte da organização que tem como perspectiva o trabalho democrático. Definir ações, em um espaço coletivo e democrático, é uma possibilidade para fortalecer o grupo no enfrentamento de conflitos e contradições, construindo a educação crítica, indispensável para as pessoas envolvidas no processo ${ }^{22}$.

Vale registrar que uma das limitações do estudo é a complexidade do fenômeno empoderamento/subjetividade e a busca de qualidade de vida. As outras duas apontam para a reduzida amostra e um único cenário, que impedem a generalização dos achados.

\section{CONCLUSÃo}

Da análise dos depoimentos dos clientes, emergirm três categorias denominadas: A vida como ela é; Potencialidades para o empoderamento; e Tecnologias - o que eu prefiro.

Com este estudo foi constatado que a tecnologia educacional pode ser usada como estratégia de empoderamento das pessoas acometidas por DCNT, considerando que durante todo o processo os participantes se envolveram no grupo, refletiram a partir da realidade do outro, aprenderam a ouvir, estimulando o raciocínio, a troca de ideias e o respeito mútuo.

A estratégia do trabalho em grupo, embora seja antiga nas salas de aula, é vantajosa e atual para as instituições de saúde. A partir desta dinâmica, foi possível conhecer os bastidores do cotidiano dos participantes, confirmando que a descoberta sobre a situação de saúde foi difícil, por mobilizar emoções, como o sentimento de tristeza, além da dor, choro e desconhecimento do processo saúde/adoecimento/ cuidado das pessoas com enfermidades crônicas.

De igual maneira foi muito positivo analisar, por meio dos depoimentos dos sujeitos, como a estratégia de dinâmica de grupo potencializou o empoderamento. Além disso, a dinâmica em grupo foi a mais desejada por eles, somando-se as palestras, conversas, panfletos informativos, entre outros.

Um dos maiores desafios deste estudo foi transformar este espaço, em um lugar crítico, problematizador sobre as questões de saúde, onde os envolvidos puderam ser ouvidos, trocar experiências, olhar para si mesmo e refletir a sua condição de saúde e, acima de tudo, não desistir de lutar pela sua qualidade de vida e autonomia.

\section{REFERÊNCIAS}

1.Ministério da Saúde (Br).Estratégias para o cuidado da pessoa com doença crônica. Cadernos de atenção básica. Brasília: (DF):MS;2014.

2.Nietsche EA, Teixeira E, Medeiros HP. Tecnologias cuidativo-educacionais: uma possibilidade para o empoderamento do/a enfermeiro. Porto Alegre (RS): Moriá; 2014

3.Merhy EE, Onoko R, organizadores. Agir em saúde: um desafio para o público. 2aed São Paulo: Hucitec; 2002.

4.Nietsche EA, Backes VMS, Colomé CLM, Ceratti RN, Ferraz F. Tecnologias educacionais, assistenciais e gerenciais: uma reflexão a partir da concepção dos docentes de enfermagem. Rev Latino-Am Enferm. 2005; 13:344-53. 5.Leite NSL, Cunha SR, Tavares MFL. Empowerment das famílias de crianças dependentes de tecnologia: desafios conceituais e a educação crítico-reflexiva freireana. Rev enferm UERJ. [periódicos na Internet]2011[citado em 11 ago 2014]; 19:152-6. Disponivel em: www.facenf. uerj.br/v19n1/v19n1a25.pdf.

6.Cordeiro RC, Azevedo EB de, Silva MSS, Filha MO, Silva PMC, Moraes MN. Terapia comunitária integrativa na estratégia da saúde da família: análise acerca dos depoimentos dos seus participantes. Revista da Universidade Vale do Rio Verde. 2011;9:192-201.

7.Hammerschmidt KSA, Lenardt MH. Tecnologia educacional inovadora para o emponderamento junto a idosos com Diabetes Mellitus. Texto contexto enferm 2010;19:358-65.

8.Carvalho SR, Gastaldo D. Promoção à saúde e empoderamento: uma reflexão a partir das perspectivas crítico-social pós-estruturalista. Rev Ciência e Saúde Coletiva [periódicos na Internet] 2008 [citado em 11 ago 2014] 13(2): 2-7. Disponível em: http://www.scielosp. org/pdf/csc/v13s2/v13s2a07.

9. Oliveira CL, Rodrigues EAS, Souza GA, Silva JS, Dias JAS, Gonçalves L, Kind, L. Uma experiência de empoderamento de mulheres na atenção primaria à saúde. Rev bras med fam comunidade. 2011; 6(21): 283-7.

10.Vasconcelos EM. A proposta de empoderamento e sua complexidade: uma revisão histórica na perspectiva do serviço social e da saúde mental. Rev Serviço Social \& Sociedade: seguridade social e cidadania. 2001; 21(65): 45-53. 11. Wendhausen ALP, Barbosa TM, Borba MC. Empoderamento e recursos para a participação em conselhos gestores. Rev Saúde sociedade. [periódicos na internet] 2006; [citado em 09 ago 2014] Disponível em: http://www.scielo.br/scielo.php?pid=S0104$12902006000300011 \&$ script $=$ sci_arttext.

12.Taddeo PS, Gomes KWL, Caprara A, Gomes AMA, Oliveira GC, Moreira TMM. Prática educativa e empoderamento de pacientes com doenças crônicas. Rev ciência saúde coletiva. 2011;17:2923-9.

13.Freire P. Pedagogia da autonomia: saberes necessários à prática educativa. 43a ed. São Paulo: Paz e Terra; 2011. 14.Buss PM. Promoción de la salud y la salud pública: una contribuición para el debate entre las escuelas de salud públic de América Latina y el Caribe. São Paulo: Abrasco; 2005.

15.Ayres JRCM. Cuidado e reconstrução das práticas de saúde.Interface, Comunicação, Saúde, Educação. 2004;8(14):72-93.

16. Bardin L. Análise de conteúdo. Lisboa $(\mathrm{Pt})$ : Edições70; 2011.

17.Berardinelli LMM, Guedes NAC, Acioli S. Hipertensão arterial e conhecimento popular: potencializando o 
cuidado. Rev enferm UERJ. 2013; 21:575-80.

18.Valoura KC. Paulo Freire, o educador brasileiro autor do termo empoderamento, em seu sentido transformador. Instituto Paulo Freire 2005. [citado em 24 ago 2014] Disponível em: http://tupi.fisica.ufmg.br/michel/docs/ Artigos_e_textos/Comportamento_organizacional/empowerment_por_paulo_freire.pdf.

19.Martins PC, Cotta RMM, Batista RS, Mendes FF, Franceschinni SCC, Priore SE, Dias G. Democracia e empoderamento no contexto da promoção da saúde: possibilidades e desafios apresentados ao Programa de Saúde da Família. Rev Pysis [periódico na internet]
2009; [citado em 12 ago 2014] 19 (3): Disponível em: http://www.scielo.br/scielo.php?script=sci_arttext\&pid $=$ S0103-73312009000300007.

20.Kleba MEW, Wendausen A. Empoderamento: processo de fortalecimento dos sujeitos nos espaços de participação social e democratização política. Saude soc. 2009; 18:733-43.

21.Czeresnia D, Freitas CM. Promoção da saúde: conceitos, reflexões, tendências. Rio de Janeiro: Fiocruz; 2003. 22.Carvalho SR. Os múltiplos sentidos da categoria empowerment no projeto de Promoção à Saúde. Cad Saúde Pública. 2004; 20:1088-95. 